Revue

Revue de l'histoire des religions

del'histoire des religions

$3 \mid 2006$

Varia

\title{
Mohammed Arkoun, Humanisme et islam. Combats et propositions
}

Paris, Vrin, 2005

Pierre Lory

\section{(2) OpenEdition}

Journals

Édition électronique

URL : http://journals.openedition.org/rhr/5179

DOI : $10.4000 /$ rhr. 5179

ISSN : 2105-2573

Éditeur

Armand Colin

Édition imprimée

Date de publication : 1 septembre 2006

Pagination : 356-358

ISBN : 2200-92105-5

ISSN : 0035-1423

Référence électronique

Pierre Lory, "Mohammed Arkoun, Humanisme et islam. Combats et propositions », Revue de l'histoire des religions [En ligne], 3 | 2006, mis en ligne le 22 janvier 2010, consulté le 10 décembre 2020. URL

http://journals.openedition.org/rhr/5179; DOl : https://doi.org/10.4000/rhr.5179

Ce document a été généré automatiquement le 10 décembre 2020.

Tous droits réservés 


\section{Mohammed Arkoun, Humanisme et islam. Combats et propositions}

Paris, Vrin, 2005

\section{Pierre Lory}

\section{RÉFÉRENCE}

Mohammed Arkoun, Humanisme et islam. Combats et propositions, Paris, Vrin, 2005, $20 \mathrm{~cm}$, 315 p., $11,50 €$

1 L'œuvre de Mohammed Arkoun - une quinzaine d'ouvrages à ce jour - occupe une place à part dans le paysage français des sciences religieuses. Elle concerne bien sûr au premier chef les études islamiques, mais sans s'y limiter. M. A. a effectué un certain nombre de recherches érudites dans un cadre académique (ainsi L'humanisme arabe au $I V^{e} / X^{e}$ siècle). Il a également rédigé des ouvrages d'intérêt plus général pour un public plus large, présentant les origines de la religion musulmane, les principaux courants anciens et actuels. Mais son apport principal aura été d'inviter, inlassablement, à réfléchir sur les bases mêmes du discours sur les religions. Il s'agit en un premier temps de démonter les mécanismes de ce qu'il appelle la raison islamique, dans les divers champs de son expression, de dénoncer les divers «bricolages idéologiques » réunissant des slogans nationalistes et religieux dans des stratégies de prise du pouvoir et de mobilisation des foules. On connaît ses efforts incessants pour ouvrir la « clôture dogmatique " dans laquelle les intellectuels musulmans ont tendance à s'enfermer. Mais M. A. invite aussi les universitaires à se défaire de l'illusion parfois naïve de l'islamologie traditionnelle, selon laquelle l'accumulation des connaissances sur les textes musulmans constitue en elle-même une science dans ce domaine.

2 Le présent ouvrage s'attache précisément à clarifier ce " désordre sémantique ». Contre l'usage de plus en plus fréquent de la «pensée jetable» et facile, consistant à ne proposer au lecteur que des notions qu'il connaît déjà, et lui éviter l'effort de la 
réflexion, il reprend un souci de s'appuyer sur une raison philosophique sans concession ni facilité. Il est constitué de six chapitres autonomes.

Dans «Retour à la question de l'humanisme en contexte islamique », M. A. revient sur l'essor de l'« humanisme laïcisant » au III ${ }^{\mathrm{e}} / \mathrm{IX}$ e siècle, avec le mu'tazilisme, la falsafa et le courant qui conduisit plus tard à l'éclosion d'un véritable humanisme, dont Miskawayh et Abû Hayyân al-Tahwîdî sont cités comme deux exemples pour l'époque bouyide. Au terme de l'évolution vers l'asservissement de cette pensée critique, il cite les principales idées-slogans de l'essayiste Anwar al-Jundî, proche des Frères Musulmans, comme exemple de " pseudo-Magistère asservi, en fait, aux Partis États » (p. 40). Dans "Conceptions du bonheur et quête du salut dans la pensée islamique ", l'auteur entend sortir les lignes de la pensée en Islam du cadre figé, essentialiste, dans lequel elles ont été enfermées par le regard occidental, avec l'active complicité de bien des auteurs musulmans, et rappelle la souplesse et le dynamisme des débats entre penseurs et courants durant la période classique. L'état actuel d'une "pensée » de consommation courante concernant l'islam est le témoin de la dégradation historique de la spéculation critique à l'époque actuelle. Les chapitres III et IV de l'ouvrage («Transgresser, déplacer, dépasser : histoire générale et histoire de la pensée » et «Pour une histoire réflexive de la pensée islamique ») donnent sans doute l'essentiel de la pensée de M. A. concernant la discipline historique. Il se met en position de dialogue avec Claude Cahen et son œuvre, et évoque les longs combats et diatribes sur la discipline historique appliquée au monde musulman. Les outils continuent souvent à manquer à ceux qui écrivent sur l'histoire du monde musulman pour en rendre compte d'une façon qui ne soit pas prisonnière de ses propres présupposés - notamment marxistes, comme dans le cas de C. Cahen, dont les analyses strictement socio-économiques conduisent par certains aspects à une impasse. Même remarque concernant une certaine «neutralité scientifique » où l'abstention n'apporte rien de fécond. Plus généralement, la vision essentialiste véhiculée par l'orientalisme traditionnel est bien plus résistante qu'il n'y paraît. La perspective de recherche renouvelée d'un Uri Rubin appliquée à la Sîra (The Eye of the Beholder, 1995) reste encore assez isolée dans le champ universitaire occidental (p. 90 et 125 sq.). Le chapitre v est consacré à la "Critique de la raison juridique dans la pensée islamique " et représente une vigoureuse mise au point, notamment au niveau de l'usage des termes et concepts ( $c f$. en particulier l'ijtihâd), des articulations du droit et, au-delà, de la politique. Enfin, des comptes rendus critiques d'ouvrages récents en islamologie (chapitre vi) fournissent une belle illustration des positions épistémologiques de M. A. concernant les études islamiques actuelles. Le livre se clôt avec l'évocation d'un souvenir de jeunesse de l'auteur dans son village de Kabylie, Taourirt-Mimoun, vivante mise en scène de la mutation des autorités dans une société islamisée.

4 M. A. constate qu'un «immense désordre sémantique a gagné les régions les plus intimes, les plus délicates, les plus essentielles de la conceptualisation dans les langues d'expression de l'islam » (p. 55). On pourrait ajouter que ce désordre sémantique gagne aussi bien les langues en usage en Europe, notamment lorsqu'elles doivent exprimer les comportements ressortissant $d u$ "religieux», et $d u$ religieux islamique tout particulièrement. C'est à l'évidence un des mérites des ouvrages de M. A. de rappeler que le chaos de la pensée - et donc de l'action - se situe, à l'origine, dans un dérèglement du langage. Patiemment, inlassablement, Mohammed Arkoun poursuit sa vocation de construction d'un langage plus vrai. 


\section{AUTEURS}

\section{PIERRE LORY}

EPHE (Sciences religieuses), Paris 